$\mathrm{PH} 103_{\text {sebate }}$

a debate Dilemas del arte urbano como patrimonio

| coordinan Elena García Gayo y Laura Luque Rodrigo

\title{
Street art y regeneración urbana en Italia
}

Andrea Areddu | Dpto. di Giurisprudenza, Università degli Studi di Sassari

URL de la contribución <www.iaph.es/revistaph/index.php/revistaph/article/view/4930>

El street art se establece en Nueva York desde los años sesenta del siglo XX para después extenderse en las décadas siguientes, de modo creciente, tanto en América como en el resto del mundo.

Dicho fenómeno artístico adquiere importancia en el ámbito social y jurídico, y es objeto de numerosas definiciones, también a nivel normativo. En particular, "por street art se entiende a aquella forma de arte que se manifiesta en lugares públicos mediante la realización de dibujos, murales, escritos, imágenes o instalaciones realizadas con cualquier material o técnica gráfica" (art. 1.2 del Regolamento per le attività di Street art del Comune di Firenze, 2016).

El street art entonces es una forma de expresión artística que se manifiesta a través de numerosas técnicas gráficas. Estas podrán estar representadas no sólo en un soporte de mampostería perteneciente a un inmueble, sino también en otros soportes como, por ejemplo, paneles, láminas de metal, calles, etc., a través de los cuales se ejecutan las diferentes obras artísticas.

Este arte tiene una capacidad de comunicación considerable ya que se manifiesta en espacios urbanos abiertos accesibles a cualquier persona, y constituye, por tanto, una expresión artística de amplio disfrute.

Hay que resaltar también la creciente difusión del arte urbano mediante el uso de las tecnologías digitales y de las social networks, que permiten una mayor difusión y disfrute de las obras artísticas para las personas, los grupos y la colectividad.

El street art es una expresión artística y cultural que dispone de numerosas referencias normativas importantes. A nivel internacional, entre los diferentes principios se pueden recordar: la Declaración Universal de Derechos Humanos (ONU, 1948), en relación con la libertad de participación en la vida cultural de la comunidad y al disfrute de las artes (art. 27); el Pacto Internacional de Derechos Económicos, Sociales y Culturales (ONU, 1966), en relación con la libertad de participación a la vida cultural, así como al desarrollo y la difusión de la cultura (art. 15); la Convención sobre la Protección y Promoción de la Diversidad de las Expresiones Culturales (UNESCO, 2005), que reconoce las numerosas expresiones culturales y artísticas de las personas, de los grupos y de la colectividad (art. 4).

En el ordenamiento jurídico de la Unión Europea, el desarrollo de la cultura y la libertad artística se tienen en cuenta en el artículo 3 del Tratado de la Unión Europea (TUE) y en el artículo 167 del Tratado de Funcionamiento de la Unión Europea (TFUE), así como en el artículo 13 de la Carta de los Derechos Fundamentales de la Unión Europea.

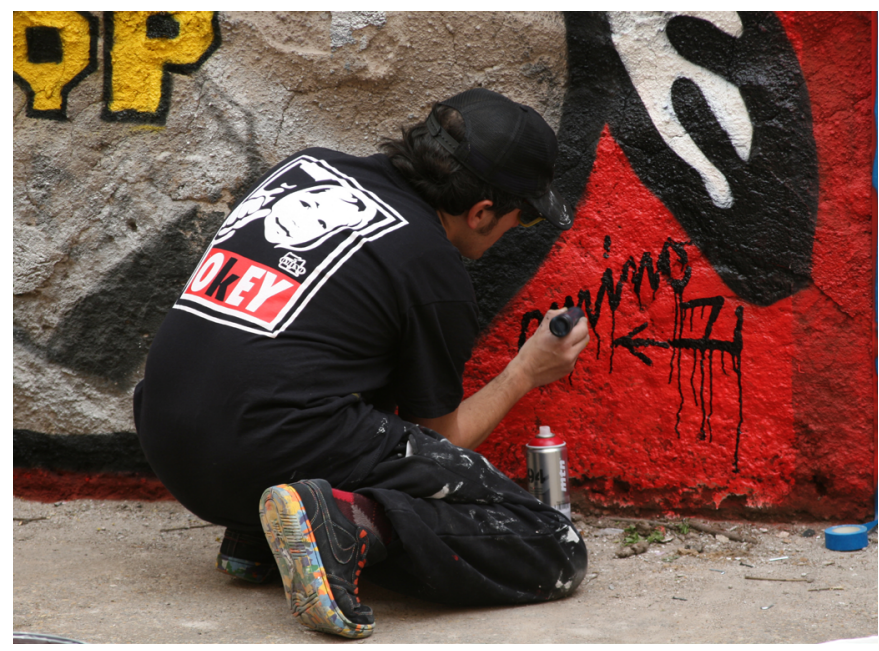

omino71 @ Collective (San Lorenzo), Roma | foto Katie Parla 
En Italia, los principios contenidos en los artículos 9 y 33 de la Constitución, respectivamente dedicados al desarrollo de la cultura y a la libertad del arte, revisten especial importancia.

En particular, el artículo 9 de la Constitución atribuye a la Repubblica, en todas sus articulaciones (Comuni, Province, Città metropolitane, Regioni y Stato), la tarea de favorecer el desarrollo de la cultura en su sentido más amplio. Por tanto, reviste una importancia fundamental el concepto de pluralismo cultural.

El artículo 33, párrafo 1, de la Constitución protege la libertad del arte en la más amplia dimensión, comprensiva de todas las expresiones artísticas.

El Código de los bienes culturales y del paisaje no regula directamente el arte contemporáneo, el arte en los espacios públicos y el street art.

Sin embargo, el street art es objeto de atención tanto en las políticas del Ministero della Cultura como en la legislación regional. En particular, por lo que se refiere a la orientación política del Ministero della Cultura, es importante señalar el comienzo de un programa específico denominado Creatività urbana in Italia, que tiene por objeto poner en práctica numerosas iniciativas relativas a la valorización del arte contemporáneo en los espacios públicos. Entre los objetivos declarados del programa figuran el reconocimiento y la cartografía digital de todas las obras de street art.

Dicho programa se sitúa en continuidad con el primer reconocimiento relativo a las obras de arte contemporáneo, que ha permitido la publicación de las obras Arte negli spazi pubblici de la plataforma ministerial Luoghi del Contemporaneo.

Además de las iniciativas del Ministero della Cultura, es importante tener en cuenta también las políticas regionales sobre el street art. Entre las leyes más recientes se recuerdan: la ley regional Puglia 16 de junio del 2020, n. 342, llamada Disposizioni per la valorizzazione, pro-

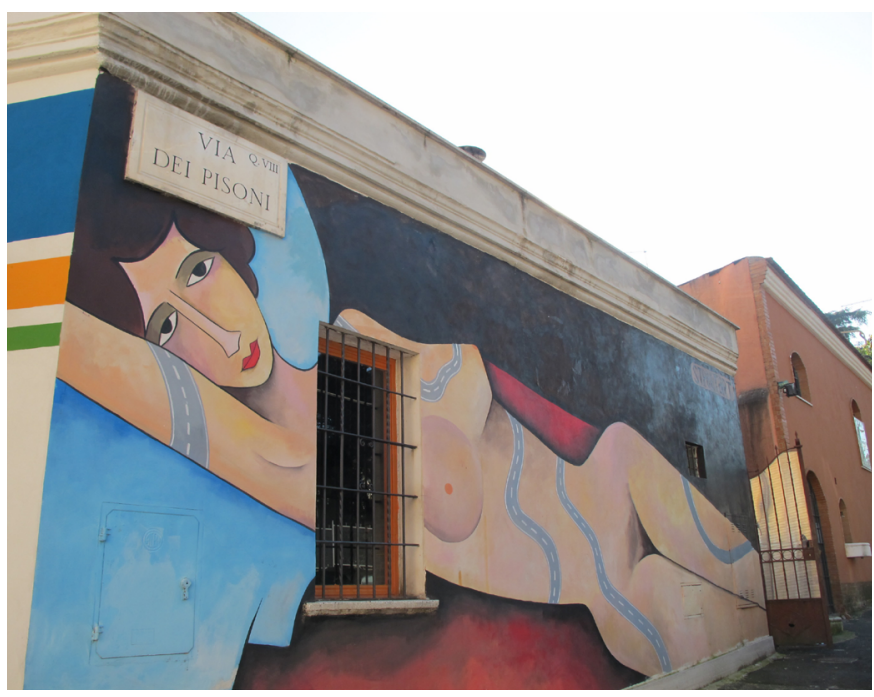

Arte urbano en Roma | foto Davide Costanzo

mozione e diffusione della Street art; la ley regional Lazio 23 de diciembre del 2020, n. ${ }^{\circ} 22$, llamada Disposizioni per la valorizzazione, promozione e diffusione della Street art.

A nivel regional, el street art se considera un fenómeno cultural con una gran capacidad de comunicación e impacto en el territorio, capaz de contribuir a la regeneración de los lugares y de los bienes de las ciudades, con especial referencia a las zonas degradadas o periféricas. Para alcanzar este objetivo se prevé la individuación de los espacios urbanos adecuados, en los que están permitidas estas expresiones artísticas. Por lo tanto, existe una relación constructiva con los ciudadanos, en particular entre los jóvenes y las instituciones públicas. También se prevén premios y catálogos regionales.

El street art asume una función creciente como instrumento de regeneración urbana también en el marco de las políticas de las administraciones locales. Hay numerosos reglamentos que permiten el arte urbano. En estos reglamentos aparecen algunos elementos para encuadrar el fenómeno artístico: se piensa en las numerosas definiciones de street art; la necesidad de identificar áreas artísticas específicas; el procedimiento de pre- 
sentación de la solicitud; la presencia de comisiones de evaluación específicas; la constitución de un registro de writers.

El tema de la regeneración urbana ahora parece imprescindible para las políticas de las administraciones y de los entes locales, también porque es capaz de involucrar numerosos intereses merecedores de protección en el marco del gobierno del territorio y de la planificación urbana: la recuperación y regeneración de los espacios urbanos; el desarrollo de la cultura, del arte y de la sociedad.

\section{BIBLIOGRAFÍA}

- Ainis M. (1991) Cultura e politica. Il modello costituzionale. Padova: CEDAM

- Barbati C., Cammelli M., Casini L., Piperata G. y Sciullo G. (2020) Diritto del patrimonio culturale. $2^{\mathrm{a}}$ ed. Bologna: II Mulino

- Bobbio N. (1955) Politica e cultura. Torino: Giulio Einaudi Editore

- Boldon Zanetti G. (2019) II diritto della Street art Santarcangelo di Romagna (RN): Maggioli Editor

- Cartei, G.F. (2017) Rigenerazione urbana e governo del territorio. Istituzioni del federalismo. Rivista di studi giuridici e politici, n. ${ }^{\circ} 3$, pp. $603-623$

- Cecchetti M. (2006) Art. 9. En: Bifulco R., Celotto A. y Olivetti M. (dir.) Commentario alla Costituzione, vol. I. Torino: Utet Giuridica, pp. 217-241

- Ciampi, M. (2017) II paradiso può attendere. La street art come forma di rigenerazione urbana. En: Galdini R. y Marata A. (dir.) La città creativa. Spazi pubblici e luoghi della quotidianità. Roma: Consiglio Nazionale Architetti Pianificatori Paesaggisti e Conservatori (CNACCP), pp. 675-683. Disponible en: http://www. cittacreative.eu/wp-content/uploads/2017/04/La citt\%C3\%A0_creativa_2017.pdf [Consulta: 18/04/2021]

- Colantonio, R. (2017) La Street art è illegale? II diritto dell'arte di strada. Napoli: Iemme Edizioni

- Comune di Firenze (2016) Regolamento per le attivita' di Street art. Deliberazione del Consiglio Comunale n. ${ }^{\circ} 47$ del 13/10/2016. Disponible en: https://www.comune.fi.it/ system/files/2017-11/Regolamento_attivita_Street_Art_0.pdf [Consulta: 16/04/2021]

- Crismani, A. (2018) Libertà dell'arte e limiti del diritto. En: AA.VV. Diritto, economia e società. In ricordo di Luisa Cusina.
Trieste: EUT Edizioni Università di Trieste, pp. 57-79

- Di Lascio F. y Giglioni F. (dir.) (2017) La rigenerazione di beni e spazi urbani. Contributo al diritto delle città. Bologna: ॥ Mulino

- Dipace, R. (2017) Le politiche di rigenerazione dei territori tra interventi legislativi e pratiche locali. Istituzioni del federalismo. Rivista di studi giuridici e politici, n. ${ }^{\circ} 3$, 2017, pp. 625-650

- D'Orsogna D. (2015) Diritti culturali per lo sviluppo umano. En: D'Orsogna D., Sacco, P.L. y Scuderi, M. (dir.) Nuove Alleanze. Diritto ed economia per la cultura e l'arte, supplemento al n. ${ }^{\circ}$ 80-81 di Arte e Critica, pp. 6-9

- D'Orsogna M. (2019) Diritto alla città e rigenerazione urbana. Esperimenti di resilienza. En: Franchini C., Paolantonio N. y Police A. (dir.) Scritti in onore di Eugenio Picozza, vol. III. Napoli: Editoriale Scientifica, pp. 2005-2052

- Ferlito, I. (2019) Diritto e Street art. Profili comparatistici. Torino: Giappichelli

- Ferri, D. (2008) La Costituzione culturale dell'Unione europea. Padova: CEDAM

- Giusti, A. (2018) La rigenerazione urbana. Temi, questioni e approcci nell'urbanistica di nuova generazione. Napoli: Editoriale Scientifica

- Mania, P., Petrilli, R. y Cristallini E. (dir.) (2017) Arte sui muri della città. Street art e urban art: questioni aperte. Roma: Round Robin

- Musco, F. (2010) Rigenerazione urbana e sostenibilità. Milano: Franco Angeli

- Passalacqua, M., Fioritto, A. y Rusci, S. (dir.) (2018) Riconoscere la Rigenerazione. Strumenti giuridici e tecniche urbanistiche. Rimini: Maggioli Editore

- Pizzorusso, A. (2000) Diritto della cultura e principi costituzionali. Quaderni costituzionali, n. ${ }^{\circ}$ 2, pp. 317-332

- Prescia, R. y Trapani, F. (dir.) (2016) Rigenerazione urbana, innovazione sociale e cultura del progetto. Milano: Franco Angeli

- Rimoli, F. (2016) La dimensione costituzionale del patrimonio culturale: spunti per una rilettura. Rivista giuridica dell'edilizia, n. ${ }^{0} 5$, pp. $505-526$

- Rimoli, F. (1992) Libertà dell'arte nell'ordinamento italiano. Padova: CEDAM

- Vecchio, N.A. (2017) A chi appartiene la citta? Sulla dialettica tra Street art e diritto. Padova: Primiceri Editore

- Zevi, A. (2010) Arte e spazio pubblico. En: AA. VV. (dir.) XXI secolo. Gli spazi e le arti. Roma-Catanzaro: Istituto della Enciclopedia Italiana fondata da Giovanni Treccani 